\title{
Failed endoscopic "over-the-scope" clip repair following iatrogenic colon perforation during screening colonoscopy
}

\author{
Anna Kane Higham ${ }^{1}$, Winifred $\mathrm{Lo}^{2}$, Arvydas Vanagunas ${ }^{3}$ and Marie Crandall ${ }^{4 *}$ \\ ${ }^{1}$ Department of Breast Surgery, Feinberg School of Medicine, Northwestern University, USA \\ ${ }^{2}$ Surgery Resident, University of Cincinnati, USA \\ ${ }^{3}$ Department of Gastroenterology and Hepatology, Feinberg School of Medicine, Northwestern University,USA \\ ${ }^{4}$ Department of Surgery, Feinberg School of Medicine, Northwestern University, USA
}

\section{Introduction}

Endoscopic closure of fistulas, leaks, and bleeding has been facilitated with the use of endoscopic clips. The Ovesco over-thescope "bear claw" device was introduced in 2008 as a new endoscopic alternative to surgical treatment of larger gastrointestinal defects than could be reliably addressed with existing endoclips. In this system, a nitinolclip is loaded on the end of an endoscope or colonoscope, and a twin grasper is used to retract the wound borders into the applicator cap using air suction. The bear claw is then applied and the defect closed; the wound is later reevaluated by scope to ensure complete closure. Further evaluation with contrast studies is often recommended as follow-up $[1,2]$. Advantages of the bear claw include the ability to close larger defects (up to $30 \mathrm{~mm}$, instead of $10 \mathrm{~mm}$ as with other endoclips), closure of full thickness defects, and availability of assist devices to better approximate the edges of defects [2]. Additionally, patients are able to undergo trial of endoscopic closure relatively quickly after identification of defect and avoid risks commonly associated with surgery. Documented uses have included successful closure of bleeding ulcers, full thickness perforations of esophagus [3,4], stomach [5], colon [6], and rectum [7], chronic fistulas and sites of post-surgical anastomotic leak. Reported success rates have ranged from $33-100 \%$ $[6,8]$.

To date, there have been few reported cases of complications related to the use of the bear claw device in endoscopic closure. Here, we report a failure of the device to close a colonic perforation as a result of routine surveillance colonoscopy.

\section{Case}

A 64-year-old white male with a family history significant for colon cancer presented for routine screening colonoscopy. Of note, he had no personal history of colon disease and had had appropriate screening since the age of 50 . During the procedure, the performing physician noted that the colonoscope was intraperitoneal, suspected near the splenic flexure. The procedure was immediately aborted. As the patient was hemodynamically stable, a flexible sigmoidoscopy was performed and an Ovesco bear claw (size 12/6T) was applied to the visualized defect. Endoscopic evaluation following clip application suggested complete closure of the defect. The patient was admitted for observation and a general surgery consultation was obtained.

On initial evaluation, the patient was hemodynamically stable with no peritoneal signs. He was managed conservatively with NPO status, IV antibiotics and close observation with serial abdominal exams in the
ICU. On post-procedure day three, however, he developed progressive abdominal distention, leukocytosis, low grade fevers and nonspecific pain in the epigastrum. He was taken emergently to the operating room for exploration with concern for persistent perforation.

Intraoperatively, significant pneumoperitoneum and $750 \mathrm{cc}$ of murky, foul-smelling fluid were found in the abdomen. Upon exploration of the colon, the bear claw device was found in the sigmoid colon with full-thickness penetration of the bowel wall. The device was embedded in the lateral abdominal wall. It was removed and the defect was repaired primarily in two layers; additionally, a loop ileostomy was created. The patient did well postoperatively and was discharged home on post-operative day seven. The loop ileostomy was reversed after three months and the patient has subsequently done well (Figure 1).

\section{Discussion}

There have been several reports of successful closure of gastrointestinal perforations, bleeding, leaks, and fistulas with this method.However, the majority of these reports involved defects in the upper gastrointestinal tract; those studies evaluating use in lower GI defects are much more limited, and studies specifically evaluating colorectal repair few. Of these, most reports describe repair failure with inability to approximate defect edges or recurrence of the repaired fistula or leak; few have described complications leading to serious morbidity or mortality in patients.

Initial studies on animal models report general success with minimal complications. In a randomized trial comparing over-the-scope closure versus open laparotomy and primary repair, complete closure was achieved in all models with no leaks, bleeding or organ injuries with the exception of small bowel wall involvement in 1 subject [9]. This was reiterated in ex vivo studies on porcine colons, where defects closed with the bear claw were able to withstand supraphysiologic burst pressures with no air leaks or failure of the clipped site [10]. In both studies, it was noted that occasionally adjacent tissue was suctioned into the applicator lumen, which needed to be repositioned by allowing

Correspondence to: Marie Crandall, MD, MPH, FACS, Associate Professor of Surgery, Feinberg School of Medicine, Northwestern University, 676 N. St. Clair, Suite 65o, Chicago, IL 60611, USA, Tel: 312695 4835; Fax: 312695 3644; E-mail: mcrandall@northwestern.edu

Received: February 15, 2015; Accepted: March 11, 2015; Published: March 15, 2015 

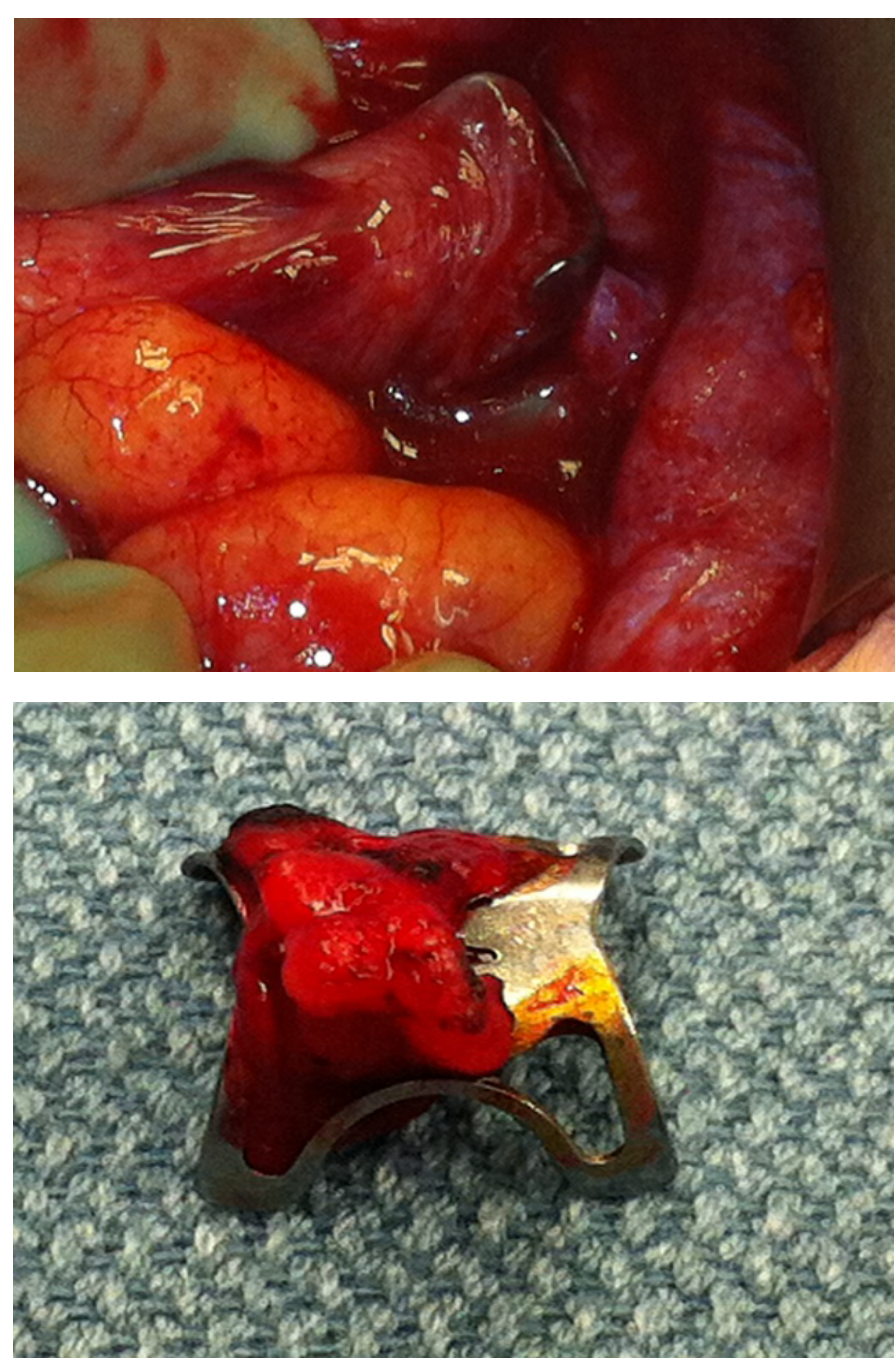

Figure 1: (left) bear claw, as identified intra operatively; (right) bear claw.

the tissue to relax or use of a twin grasper before applying the clip itself $[9,10]$.

In human studies, there have been several reports of difficulty using the bear claw and no previous reports of serious complications resulting from use of the bear claw. To our knowledge, there have been a total of 50 cases of colonic perforation repair [11-20]. Of these, there were 9 reported complications includingpain due to fat incarceration [17], unsuccessful closure of the defect $[12,13,17,20]$ stenosis of the transverse colon [19] and one instance where the patient rapidly deteriorated and died soon after the defect was repaired [16]. This death was believed to be unrelated to the repair itself and was attributed to sepsis secondary to the initial perforation [16]. Otherwise, common difficulties noted include widening of the defect's original dimensions by inappropriate suctioning of wound borders, poor approximation of defect edges and inability to secure the wound borders due to friable or necrotic tissue [17].

Moreover, in a brief review of published reports in the last 18 months (January 2012-June 2013), there is a discrepancy in the frequency of complications for upper GI versus lower GI defect repairs. Of UGI studies, there were a total of 101 patients treated with 11 complications (complication rate of 10.9\%). For LGI studies, there were a total of 41 patients treated, resulting in 6 complications
Table 1. Published data on use of over-the-scope clips to repair colorectal defects in patients and subsequent complications. *rectal perforation.

\begin{tabular}{|l|c|l|}
\hline Study & $\begin{array}{c}\text { \# patients } \\
\text { undergoing } \\
\text { closure }\end{array}$ & Complications noted \\
\hline Manta et al., 2013 & 1 & None \\
\hline Menningen et al., 2013 & 5 & $\begin{array}{l}\text { Incomplete closure of fistula requiring subsequent } \\
\text { surgical repair (2 patients) }\end{array}$ \\
\hline Gray et al., 2012 & 1 & Incomplete closure of fistula (1 patient) \\
\hline Coker et al., 2012 & 1 & $\begin{array}{l}\text { Procedure aborted due to inability to pass scope } \\
\text { and clip past epiglottis (1 patient) }\end{array}$ \\
\hline Baron et al., 2012 & 11 & None \\
\hline Voermans et al., 2012 & 13 & Deterioration and death within 36 h (1 patient) \\
\hline Hagel et al., 2012* & 2 & None \\
\hline Jovanovic et al., 2012 & 6 & Unsuccessful closure (1 patient) \\
\hline Kirschniak 2011 & 4 & None \\
\hline Seebach et al., 2010 & 3 & $\begin{array}{l}\text { Pain secondary to fat incarceration (1 patient), } \\
\text { unsuccessful closure (1 patient) }\end{array}$ \\
\hline Parodi et al., 2010 & 1 & None \\
\hline Kirschniak et al., 2007 & 2 & $\begin{array}{l}\text { Stenosis of transverse colon, free air in peritoneum } \\
\text { following intervention (1 patient) }\end{array}$ \\
\hline
\end{tabular}

(complication rate of 14.6\%). Gross comparison of reports for UGI versus LGI studies suggests that colorectal defects tend to be larger and more clinically significant, thus leading to a higher frequency of necessitating subsequent surgical repair (Table 1).

Finally, the quality of research describing "success" in using the bear claw is significantly varied. The majority of reports are retrospective or prospective cohorts, with few instances of randomized control trials to fairly evaluate the difference between endoscopic and surgical repair options. Additionally, many of these reports collect isolated instances of successful repair anywhere throughout the GI tract, including reports of esophageal, stomach, duodenal and colonic defect repair in the same article for summative analyses. Most concerning is the absence of documentation of average and maximum defect diameters; this complicates analysis of existing data as closing a 1-2 mm esophageal fistula is different from repair of a $30 \mathrm{~mm}$ colonic defect.

First, we recommend that only patients with uncomplicated perforations are considered for endoscopic repair; those patients with history of colon cancer or other colonic disease be excluded from consideration. Prior studies resulting in unsuccessful closure have indicated that tissue friability surrounding the defect is a significant limiting factor. Furthermore, given the necessity of healthy tissue at the borders of wound defects, it would be unwise to challenge the integrity of the repaired defect with residual disease. Additionally, though the manufacturer advertises use for defects as large as $30 \mathrm{~mm}$, there is limited data suggesting the maximum defect that can be repaired with the bear claw and poor evidence to show that the device can adequately close $30 \mathrm{~mm}$ defects. Thus, those patients with colon perforations greater than $30 \mathrm{~mm}$ in size should be deferred for surgical intervention with no attempt at endoscopic repair; patients whose defects are repaired endoscopically with the bear claw should be closely monitored for signs of peritonitis or persistent leak with low threshold for surgical intervention until stronger data is available.

\section{Conclusion}

Here, we report the first known serious complication in published literature associated with the bear claw over-the-scope clip for large colonic perforation. While preliminary studies have suggested that this device is relatively easy and safe to use, this experience mandates that 
more selective criteria need to be used to distinguish those patients who are eligible for this method of repair versus surgical repair.

\section{References}

1. Arezzo A,Verra M, Reddavid R, Cravero F, Bonino MA, et al. (2012) Efficacy of the over-the-scope clip (OTSC) for treatment of colorectal postsurgical leaks and fistulas. Surg Endosc 26: 3330-3333. [Crossref]

2. Kirschniak A, Subotova N, Zieker D, Königsrainer A, Kratt T (2011) The Over-TheScope Clip (OTSC) for the treatment of gastrointestinal bleeding, perforations, and fistulas. Surg Endosc 25: 2901-2905. [Crossref]

3. Galizia G, Napolitano V, Castellano P, Pinto M, Zamboli A, et al. (2012) The Over-TheScope-Clip (OTSC) system is effective in the treatment of chronic esophagojejunal anastomotic leakage. J Gastrointest Surg 16: 1585-1589. [Crossref]

4. Zolotarevsky E, Kwon Y, Bains M, Schattner M (2012) Esophagobronchial fistula closure using a novel endoscopic over-the-scope-clip. Ann Thorac Surg 94: e69-70. [Crossref]

5. Vormbrock K, Zabielski M, Mönkemüller K (2012) Use of the "bear claw" (over-thescope-clip) to achieve hemostasis of a large gastric ulcer with bleeding visible vessel. Gastrointest Endosc 76: 917-918. [Crossref]

6. Disibeyaz S, Koksal AS, Parlak E, Torun S, Sasmaz N (2012) Endoscopic closure of gastrointestinal defects with an over-the-scope clip device. A case series and review of the literature. Clin Res Hepatol Gastroenterol 36: 614-621. [Crossref]

7. Mori H, Kobara H, Fujihara S, Nishiyama N, Kobayashi M, et al. (2012) Rectal perforations and fistulae secondary to a glycerin enema: closure by over-the-scope-clip. World J Gastroenterol 18: 3177-3180. [Crossref]

8. Surace M, Mercky P, Demarquay JF, Gonzalez JM, Dumas R, et al. (2011) Endoscopic management of GI fistulae with the over-the-scope clip system (with video). Gastrointest Endosc 74: 1416-1419. [Crossref]

9. von Renteln D, Schmidt A, Vassiliou MC, Rudolph HU, Gieselmann M, et al. (2009) Endoscopic closure of large colonic perforations using an over-the-scope clip: a randomized controlled porcine study. Endoscopy 41: 481-486. [Crossref]

10. Matthes K, Jung Y, Kato M, Gromski MA, Chuttani R (2011) Efficacy of full-thickness GI perforation closure with a novel over-the-scope clip application device: an animal study. Gastrointest Endosc 74: 1369-1375. [Crossref]
11. Manta R, Galloro G, Mangiavillano B, Conigliaro R, Pasquale L, et al. (2013) Over-thescope clip (OTSC) represents an effective endoscopic treatment for acute GI bleeding after failure of conventional techniques. Surg Endosc 27: 3162-3164. [Crossref]

12. Mennigen R, Colombo-Benkmann M, Senninger N, Laukoetter M (2013) Endoscopic closure of postoperative gastrointestinal leakages and fistulas with the Over-the-Scope Clip (OTSC). J Gastrointest Surg 17: 1058-1065. [Crossref]

13. Gray DM 2nd, Mullady DK (2012)Attempted endoscopic closure of a pancreaticocolonic fistula with an over-the-scope clip. JOP 13: 712-714. [Crossref]

14. Jacobsen GR, Coker AM, Acosta G, Talamini MA, Savides TJ, et al. (2012) Initial experience with an innovative endoscopic clipping system. Surg Technol Int 22: 39-43. [Crossref]

15. Voermans RP, Le Moine O, von Renteln D, Ponchon T, Giovannini M, et al. (2012) Efficacy of endoscopic closure of acute perforations of the gastrointestinal tract. Clin Gastroenterol Hepatol 10: 603-608. [Crossref]

16. Hagel AF, Naegel A, Lindner AS, Kessler H, Matzel K, et al. (2012) Over-the-scope clip application yields a high rate of closure in gastrointestinal perforations and may reduce emergency surgery. J Gastrointest Surg 16: 2132-2138. [Crossref]

17. Seebach L, Bauerfeind P, Gubler C (2010) "Sparing the surgeon": clinical experience with over-the-scope clips for gastrointestinal perforation. Endoscopy 42: 1108-1111. [Crossref]

18. Parodi A, Repici A, Pedroni A, Blanchi S, Conio M (2010) Endoscopic management of GI perforations with a new over-the-scope clip device (with videos). Gastrointest Endosc 72: 881-886. [Crossref]

19. Kirschniak A, Kratt T, Stuker D, Braun A, Schurr MO, et al. (2007) "A new endoscopic over-the-scope clip system for treatment of lesions and bleeding in the GI tract: first clinical experiences." Gastrointest Endosc 66: 163-167. [Crossref]

20. Jovanovic I, Zimmermann L, Fry LC, Mönkemüller K (2011) Feasibility of endoscopic closure of an iatrogenic colon perforation occurring during colonoscopy. Gastrointest Endosc 73: 550-555. [Crossref]

21. Voermans RP,Vergouwe F, Breedveld P, Fockens P, van Berge Henegouwen MI (2011) Comparison of endoscopic closure modalities for standardized colonic perforations in a porcine colon model. Endoscopy 43: 217-222. [Crossref]

22. Schurr MO, Hartmann C, Ho CN, Fleisch C, Kirschniak A (2008) An over-thescope clip (OTSC) system for closure of iatrogenic colon perforations: results of an experimental survival study in pigs. Endoscopy 40: 584-588. [Crossref]

Copyright: $(2015$ Higham AK. This is an open-access article distributed under the terms of the Creative Commons Attribution License, which permits unrestricted use, distribution, and reproduction in any medium, provided the original author and source are credited. 